\title{
A Twin Study of Posttraumatic Stress Disorder Symptoms and Chronic Widespread Pain
}

\author{
Dr. Lester M. Arguelles, Ph.D., Dr. Niloofar Afari, Ph.D., Dr. Dedra Buchwald, MD, Dr. Daniel \\ Clauw, MD, Dr. Sylvia Furner, Ph.D., and Dr. Jack Goldberg, Ph.D. \\ Department of Epidemiology and Biostatistics, University of Illinois at Chicago, School of Public \\ Health (Dr. Arguelles, Dr. Furner), Chicago, IL; the Departments of Medicine (Dr. Buchwald), \\ Psychiatry and Behavioral Sciences (Dr. Afari), and Epidemiology (Dr. Goldberg), University of \\ Washington, and the Vietnam Era Twin Registry, VA Puget Sound Health Care System (Dr. \\ Goldberg), Seattle, WA; and the Department of Medicine, University of Michigan (Dr. Clauw), Ann \\ Arbor, MI
}

\section{Abstract}

Previous studies of the association between posttraumatic stress disorder (PTSD) and chronic widespread pain (CWP) or fibromyalgia have not examined the role of familial or genetic factors. The goals of this study were to determine if symptoms of PTSD are related to CWP in a genetically informative community-based sample of twin pairs, and if so, to ascertain if the association is due to familial or genetic factors. Data were obtained from the University of Washington Twin Registry, which contains 1,042 monozygotic and 828 dizygotic twin pairs. To assess the symptoms of PTSD, we used questions from the Impact of Events Scale (IES). IES scores were partitioned into terciles. CWP was defined as pain located in 3 body regions lasting at least 1 week during the past 3 months. Random effects regression models, adjusted for demographic features and depression, examined the relationship between IES and CWP. IES scores were strongly associated with CWP $(P<0.0001)$. Compared to those in the lowest IES tercile, twins in the highest tercile were 3.2 times more likely to report CWP. Although IES scores were associated with CWP more strongly among dizygotic than among monozygotic twins, this difference was not significant. Our findings suggest that PTSD symptoms, as measured by IES, are strongly linked to CWP, but this association is not explained by a common familial or genetic vulnerability to both conditions. Future research is needed to understand the temporal association of PTSD and CWP, as well as the physiological underpinnings of this relationship.

\section{Keywords}

Chronic widespread pain; Fibromyalgia; Genetic; Posttraumatic stress disorder; Twins

\section{INTRODUCTION}

Chronic widespread pain (CWP) is a common problem in the general population, with an estimated prevalence ranging from $7 \%$ to $13 \%$ across different countries (Neumann and Buskila 2003). The American College of Rheumatology defines CWP as pain present in at least 2 contra-lateral body quadrants and the axial skeleton that has persisted for at least 3 months (Wolfe et al. 1990). Many experts believe that both CWP and fibromyalgia (FM), a

Reprint requests and correspondence should be sent to Niloofar Afari, University of Washington, Department of Psychiatry and Behavioral Sciences, $3259^{\text {th }}$ Avenue, Box 359780, Seattle, WA 98104, Telephone: (425) 941-8709, Fax: (206) 543-3830, afari@u.washington.edu. 
severe subtype of CWP, represent one end of the spectrum of musculoskeletal pain disorders (Croft 2000; Croft et al. 1996; Wolfe 1997). CWP has a modest female predominance and its prevalence increases with age (Bergman et al. 2002; Buskila et al. 2000; Hunt et al. 1999). People with CWP also experience poor subjective health, fatigue, sleep disruption, and physical impairments (Aaron et al. 2002; Prescott and Jacobsen 1993). Despite a growing body of literature, the etiology and pathophysiology of CWP remain poorly understood. Recently, several studies have documented that CWP and FM are strongly associated both with the symptoms of posttraumatic stress disorder (PTSD) (Walter et al. 1998; White et al. 2002; Wolfe and Skevington 2000) and with the clinically diagnosed disorder itself (Benedikt and Kolb 1986; Benjamin et al. 2000; Cohen et al. 2002; Roy-Byrne et al. 2004). Conversely, high rates of CWP and FM also have been observed among persons with PTSD (Amir et al. 1997; Dobie et al. 2004; Raphael et al. 2004).

Clinic-based studies have shown that PTSD and CWP, persistent pain, or fibromyalgia were strongly associated, but the link was potentially attributable to the biases inherent in using clinical samples (Aaron et al. 1996; Crook et al. 1989; Macfarlane et al. 1999). Results from population-based studies, however, have substantiated both the existence and the strength of the association (Benjamin et al. 2000; Buchwald et al. 2005). Additionally, both PTSD and FM are thought to be partially heritable. Family studies have shown that FM aggregates strongly in families (Arnold et al. 2004; Buskila and Neumann 1997; Buskila et al. 1996; Pellegrino et al. 1989), but linkage studies have found either a weak linkage or none at all (Gursoy 2002; Yunus et al. 1999). Investigations into the heritability of PTSD have shown that PTSD is related to family history of psychiatric illness (Davidson et al. 1989; Koenen et al. 2002; Koenen et al. 2003).

No previous investigation has controlled for genetic or environmental influences on the relationship between PTSD and CWP. This study addresses some of these limitations by examining the association of PTSD and CWP in a sample of twins enrolled in a communitybased registry in Washington State. In these analyses, we address the following questions: 1) Are the symptoms of PTSD and CWP associated? If so, 2) Do familial/genetic factors account for the association of PTSD symptoms and CWP?

\section{METHODS}

\section{Sample}

The University of Washington Twin Registry is a community-based sample of twins derived from the drivers' license applications of the Washington State Department of Licensing. Unique to Washington State, drivers' license numbers are derived from a person's last name, first and middle initials, and date of birth. In the past, this led to the issuance of duplicate drivers' license numbers. Hence the Department of Licensing began asking every new applicant if he or she is a member of a twin pair to avoid issuing duplicate license numbers to twins. Because Washington State agencies are permitted by law to share data, the Department of Licensing has provided a list of all new drivers' license applicants who are twins to the University of Washington since 1998. Upon receiving the names from the Department of Licensing, the University of Washington Twin Registry staff sends each twin an invitation to join, a brief survey to complete, and an incentive. If the twin does not respond within one month, a second invitation and survey are mailed. The co-twin is mailed a survey using contact information provided by the index twin. To date, the University of Washington Twin Registry has enrolled 1042 monozygotic (MZ) pairs, 828 dizygotic (DZ) pairs, and 121 pairs of undetermined zygosity. The University of Washington Human Subjects Review Committee approved the procedures for establishing the twin registry and all data collection involved in this study. Informed consent was obtained from all participants. 


\section{Survey}

The survey contains items on demographics, symptoms, physician-diagnosed health conditions including PTSD and depression, habits, health care use, and abridged psychiatric measures, such as the Impact of Events Scale (IES) (Horowitz et al. 1979) and a modified version of the London Fibromyalgia Epidemiology Study Screening Questionnaire (White et al. 1999).

\section{Zygosity Assignment}

As part of the mailed questionnaire all twins were asked questions about childhood similarity to assess zygosity. Studies have shown that questions about childhood similarity in twin pairs can be used to correctly classify zygosity with an accuracy of 95-98\%, in comparison with zygosity determined by biological indicators (Eisen et al. 1989; Torgersen 1979). The following questions were asked: "As children were you and your twin as alike as 2 peas in a pod or of ordinary family resemblance?" and "When you were children how often did [parents, other relatives, teachers, strangers] have difficulty in telling you apart?" The responses to these similarity questions were then used in a multi-step process to assign zygosity.

\section{Sociodemographic Factors and Clinical Conditions}

Sociodemographic factors collected in the survey included age, race, gender, education, and marital status. Age was calculated from the year of birth. The twins were asked if they were White, Black, Asian/Pacific Islander, Native American, Hispanic/Latino, or other. We dichotomized responses to White or other. Marital status was assessed by asking the twin whether he or she was currently single, never married, living with a partner, married, separated, divorced, or widowed. This variable was dichotomized to married or other. For education, we asked about the highest level of education completed (kindergarten to graduate school). One question inquired about a physician diagnosis of depression and another about a physician diagnosis of PTSD. Because studies have shown body mass index and depression to be strongly associated with CWP and FM (McBeth et al. 2001; Yunus et al. 2002) as well as with PTSD (Karlovic et al. 2004; Solter et al. 2002), these variables were included as covariates in the regression models to adjust for their potentially confounding effects.

\section{Posttraumatic Stress Disorder Symptoms}

PTSD is a disorder in which an overwhelming traumatic event results in intense fear, helplessness, horror, and avoidance of stimuli associated with the trauma (American Psychiatric Association 1994). PTSD symptoms were identified by using the IES, which assesses current subjective distress resulting from a stressful life event. Because individuals with PTSD are often reluctant to seek evaluation and treatment (Amaya-Jackson et al. 1999), we did not use the self-report of a physician diagnosis of PTSD. The IES captures qualities of conscious experience that encompass stressful life events, such as bereavement or personal injuries from accidents, violence, illness, or surgery (Horowitz et al. 1979). Although the IES is a measure only of the DSM-IV intrusion and avoidance symptom criteria for PTSD (American Psychiatric Association 1994), previous studies have shown the IES to be strongly correlated with a diagnosis of PTSD. For example, a Dutch study of pain and stress in burn victims found that IES scores > 26 were indicative of serious PTSD (Taal and Faber 1997). As a screening measure for PTSD, the sensitivity of the IES ranges from 0.94 to 1.00 and the specificity ranges from 0.78 to 0.84 (Wohlfarth et al. 2003). More recently, it has been suggested that additional items on hyper-arousal could be added to the IES (Weiss and Marmar 1997).

We used 11 of the 15 original IES items, deleting 4 of the original items based on the cluster analysis that was conducted by the developers of the IES. These items had the poorest correlation with the IES intrusion and avoidance subscales (Horowitz et al. 1979). Internal 
reliability of the IES was assessed by using Cronbach's alpha and validity was evaluated by its concordance with a self-report of PTSD diagnosed by a physician. For the 11 IES items used in this analysis, the Cronbach's alpha was 0.90, indicating a high degree of internal consistency. Likewise, the validity of the IES was demonstrated by a strong trend between the IES and a physician diagnosis of PTSD $\left(X^{2}\right.$ trend $\left.=59.3, P<0.0001\right)$.

Each IES item has 4 response categories $(0=$ not at all, $1=$ rarely, $3=$ sometimes, $5=$ often $)$. These values are summed to create an overall score (range 0-55). We grouped the scores into terciles representing increasing levels of current subjective distress: 0-6 (lowest distress), 724 (moderate distress), and 25+ (highest distress). We included only twins who answered at least 6 of the 11 IES items, and as previously recommended, missing values were imputed by using the respondent's average score across completed items (Ware et al. 1980). For example, if a twin did not answer 2 IES items, we used the mean score across the 9 completed items to impute values for the missing items.

\section{Chronic Widespread Pain}

The survey included 3 of 4 questions about CWP adapted from the self-report form of the London Fibromyalgia Epidemiology Study Screening Questionnaire (White et al. 1999). Our questions also were similar to those used in several European population-based studies, conducted by mail and telephone interviews, on the prevalence of chronic pain (Allison et al. 2002; Croft et al. 1993; Macfarlane et al. 2001; Papageorgiou et al. 2002; Smith et al. 2001). Twins were asked about body pain in 3 regions as follows: "In the past 3 months have you had pain in your muscles, bones, or joints lasting at least one week in your: 1) shoulders, arms, or hands? 2) legs or feet? 3) neck, chest, or, back?". CWP was defined as pain experienced in all 3 regions.

\section{Statistical Analysis}

Initial descriptive analyses examined the distribution of sociodemographic factors and depression according to IES tercile. The trend across terciles of these variables was statistically tested by using a Chi-square test for trend for proportions or a one-way ANOVA for means. To investigate the association of the IES with CWP, a random-effects model was fitted to the twin data (Goldstein 1995). This approach is appropriate because observations within twin pairs cannot be assumed to be statistically independent, an assumption which classical statistical approaches make for estimation and testing. This type of data is considered to be multilevel or clustered, where twins are the cluster. The random-effects model accounts for the lack of independence by using a random-effects term to model the between-pair variance. Additionally, these models can be used with incomplete data, so that half-pairs (in which data on CWP are available from only one member of a pair) can still contribute to portions of the estimation and testing.

We initially modeled the association between the IES and CWP to estimate the overall effect in all twin pairs. In the analysis, we created indicator variables for each tercile of the IES, with the lowest tercile serving as the reference level, to obtain odds ratios and 95\% confidence intervals. To statistically test for trend, we conducted an analysis using the continuous IES scores. This overall model specification represents a weighted average of within- and betweenpair information (Begg and Parides 2003). We then obtained separate estimates of the IESCWP association within and between pairs. In this context, the between-pair effects are an estimate of the IES-CWP association unadjusted for familial environment and genetic influence, whereas the within-pair effects are adjusted for shared familial influences in DZ twins and both shared familial and genetic influences in MZ twins. If adjusting for factors that twins share (i.e., shared familial environment and genetics), eliminates the association between IES and CWP as seen in the within-pair effect, then it is possible to conclude that these shared 
factors contribute to the IES-CWP association. Alternately, if the adjusted association (withinpair effect) is attenuated but still significant, it suggests that the IES-CWP association in part is explained by shared familial factors in DZ twins and familial and genetics factors in MZ twins. Lastly, if within-pair and between-pair effects are similar, it suggests that familial and genetic factors may not play a significant role in the association between IES and CWP.

In our subsequent modeling, we specified within and between effects separately for MZ and DZ pairs. The DZ within-pair odds ratios are adjusted for familial as well as some genetic influences; DZ twins share a similar family environment, but they share only $50 \%$ of their genes on average. Because MZ twins share identical genes, the within-pair effect is an estimate adjusted for both familial and genetic factors. Thus, significantly greater within-pair effects for DZ than MZ twins would suggest shared genetic influence on both CWP and IES. The resulting odds ratios were adjusted for age, sex, race, marital status, education, body mass index, and depression. We used SAS software, Version 8.2 for all statistical analyses (SAS Institute 2000).

\section{RESULTS}

Table 1 describes the demographic and clinical characteristics of the entire sample and across terciles of IES scores. More than 55\% of the sample consisted of MZ twins, the mean age was 33 years old, $61 \%$ of the twins were female, and $62 \%$ had some college education. The prevalence of self-reported depression was $20 \%$. We observed an increasing trend of CWP, self-reported PTSD and depression, and female gender with higher IES scores $\left(P_{\text {trend }}<0.01\right)$. Conversely being married and having higher graduate-level education was associated with lower IES scores $\left(P_{\text {trend }}<0.01\right)$.

Table 2 presents unadjusted odds ratios and $95 \%$ confidence intervals for the association of the IES with CWP in all twins and separately for MZ and DZ pairs. There was a strong and highly significant association between the IES score and CWP in all twins $\left(P_{\text {trend }}<0.0001\right)$. Compared to those in the lowest IES tercile, twins in the highest IES tercile were 3.2 times more likely to report CWP. A similar pattern was observed in both MZ and DZ twin pairs.

Table 3 displays the between- and within-pair associations of the IES and CWP separately in MZ and DZ pairs, adjusted for age, sex, race, marital status, education, body mass index, and depression. The between-pair effects in $\mathrm{MZ}$ and DZ twins showed a strong association of IES with CWP $\left(P_{\text {trend }}=0.01\right.$ in MZ pairs; $P_{\text {trend }}=0.01$ in DZ pairs $)$, but did not differ according to zygosity $(P=0.95)$. Within-pair trends were significant in both MZ $\left(P_{\text {trend }}=0.04\right)$ and DZ pairs $\left(P_{\text {trend }}=0.01\right)$. After adjusting for sociodemographic factors, depression, and familial and genetic influences, MZ and DZ twins at the highest IES tercile were 2.6 to 3.0 times more likely to report CWP than twins in the lowest tercile, suggesting that shared familial and genetic factors may not contribute to the relationship between IES scores and CWP. Although the within-pair effect for DZ twins was slightly larger than that found for MZ twins, the difference was not significant $(P=0.52)$.

\section{DISCUSSION}

We found that symptoms of PTSD, as measured by the IES, were strongly related to the presence of CWP. Further, the increased prevalence of CWP across terciles of increasing IES scores was strong and significant even after adjusting for demographic factors and depression. These results are congruent with several other studies. Clinical studies of FM patients have found high rates of PTSD or PTSD symptoms (Benedikt and Kolb 1986; Cohen et al. 2002; Sharp 2004; Sherman et al. 2000), and studies conducted in pain clinic patients, female veterans, and a community sample of women have found that individuals diagnosed with FM 
are at $\sim 3$-fold increased risk of experiencing PTSD or PTSD symptoms compared to those without FM (Dobie et al. 2004; Raphael et al. 2004; Roy-Byrne et al. 2004). Taken together, these previous studies have confirmed the association between PTSD and CWP, although none of them adjusted for genetic and shared environmental influences on this relationship.

This is the first study of PTSD symptoms and CWP in a twin population. Several previous studies have demonstrated that both PTSD and CWP in individuals have a familial or genetic component. For example, a family study of Cambodian refugees living in the United States found that parental PTSD was associated with a 5-fold increased risk of PTSD in their offspring (Sack et al. 1995). Findings from a study of male twins from the Vietnam Era Twin Registry suggested that a shared familial vulnerability contributes to the co-occurrence of PTSD and major depression and that genetic factors may mediate this vulnerability (Koenen et al. 2003). Similarly, studies of FM have demonstrated a familial or genetic influence. For example, a high prevalence of FM has been found repeatedly among offspring of mothers with FM, and relatives of people with FM have a lower tender point threshold than the general population (Arnold et al. 2004; Buskila et al. 1996). Another study showed that husbands of women with FM had a high prevalence of FM (Buskila and Neumann 1997). This is intriguing, because the prevalence of FM in men is substantially lower than in women (Yunus 2001; Yunus 2002) and, more importantly, because familial or environmental influences would be implicated in this association, rather than genetic ones.

Twin studies of other pain conditions also have demonstrated familial and genetic influences. One study of low back and neck pain found that these conditions may be highly heritable, with $52-68 \%$ of the variance for low back pain and $35-58 \%$ of the variance for neck pain attributable to gene factors (MacGregor et al. 2004). Conversely, a twin study of temporomandibular joint disorder found that environmental factors were the major determinants of variance

(Michalowicz et al. 2000). In our study, we examined whether the relationship between PTSD symptoms and CWP was due to familial or genetic factors. The MZ and DZ within-pair effects were similar to the between-pair effects, suggesting that familial factors do not play a role in the relationship between CWP and PTSD symptoms. Likewise, the MZ within-pair effect was only slightly attenuated compared to the DZ within-pair effect. These findings suggest that the strong association between PTSD symptoms and CWP cannot be explained by confounding due to genetic influences. Thus, one can conclude that individual differences in trauma may explain the robust association between PTSD symptoms and CWP. There are, however, other possible factors that vary within a pair, for example marital status or social support, which could also confound this relationship.

Although some evidence now exists to support the relationship between PTSD and CWP, the mechanisms remain enigmatic. The relationship between PTSD and CWP has been postulated to be mutually maintaining, where CWP serves as a traumatic stimulus for the development of PTSD, and the hyper-arousal, stress intolerance, and selective attention typical of PTSD worsen the pain (Sharp and Harvey 2001). Other researchers have proposed a model of shared vulnerability, in which the relationship of PTSD and pain are mediated by a third factor, such as anxiety sensitivity, which increases vulnerability either to PTSD symptoms or to pain (Asmundson et al. 2002). Still others postulate that baseline abnormalities in hypothalamic pituitary adrenal and autonomic function may serve as a diathesis that predisposes to either CWP or PTSD or both after a traumatic event (McLean et al. 2005). Studies using brain imaging methods, such as functional MRI, to investigate how the brain reacts to psychological trauma and pain have found that pain is processed in more regions than previously thought, and that some of these overlap with regions activated with psychological trauma (Coghill et al. 1999; Shin et al. 1997). Understanding the patterns and linkages of the overlapping brain regions involved in the experience of pain and trauma could shed light on this intriguing association. Regardless of the underlying mechanism, however, our findings strongly support the need to 
assess for PTSD and CWP comorbidity and to provide adequate treatment for the symptoms of both disorders.

This study has several limitations. First, although the IES has been used extensively as a measure of PTSD symptoms, we were unable to use the complete 15-question version. While the 4 questions eliminated were those least correlated with their respective intrusion or avoidance subscale measures, we are unable to examine the impact of these deletions on the true score. However, the internal consistency of the 11 questions that were retained was quite high. Second, the IES is an indicator of PTSD symptoms that is not anchored to a specific traumatic experience, so the severity or impact of the traumatic experience is unclear. When used in this manner, the IES may in part be measuring a "trait" rather than a "state" (i.e., a stereotypical response to many traumatic events rather than a specific response to a single event). Finally, our measure of CWP is not ideal because it was designed to screen for FM during a telephone interview. Although $100 \%$ sensitive for FM and $100 \%$ specific for the absence of pain, the screener has an estimated specificity of $57 \%$ and a false positive rate of $43 \%$ among individuals with other forms of chronic pain such as rheumatoid arthritis.

In conclusion, our analysis was based on a large, unselected sample of twins identified from the community of licensed drivers in Washington State. Previous studies of PTSD and CWP typically have involved clinical samples with unknown selection biases. We found a strong association between PTSD symptoms and CWP that was not explained by a shared familial or genetic vulnerability to both conditions. Future studies need to examine the viability of mutual maintenance and shared vulnerability models, as well as the central nervous system mechanisms that may play a role in the link between PTSD and pain.

\section{Acknowledgments}

This research was supported by National Institutes of Health awards 5 U19 AI38429-08 (Buchwald) and R55AR051524 (Afari).

\section{References}

Aaron LA, Arguelles LM, Ashton S, Belcourt M, Herrell R, Goldberg J, Smith WR, Buchwald D. Health and functional status of twins with chronic regional and widespread pain. J Rheumatol 2002;29:242634. [PubMed: 12415604]

Aaron LA, Bradley LA, Alarcon GS, Alexander RW, Triana-Alexander M, Martin MY, Alberts KR. Psychiatric diagnoses in patients with fibromyalgia are related to health care-seeking behavior rather than to illness. Arthritis Rheum 1996;39:436-45. [PubMed: 8607892]

Allison TR, Symmons DP, Brammah T, Haynes P, Rogers A, Roxby M, Urwin M. Musculoskeletal pain is more generalised among people from ethnic minorities than among white people in Greater Manchester. Ann Rheum Dis 2002;61:151-6. [PubMed: 11796402]

Amaya-Jackson L, Davidson J, Hughes D, Swartz M, Reynolds V, George L, Blazer D. Functional impairment and utilization of services associated with posttraumatic stress in the community. J Trauma Stress 1999;12:709-24. [PubMed: 10646189]

American Psychiatric Association. Diagnostic and Statistical Manual of Mental Disorders (DSM-IV). American Psychiatric Association; Washington, D.C.: 1994.

Amir M, Kaplan Z, Neumann L, Sharabani R, Shani N, Buskila D. Posttraumatic stress disorder, tenderness and fibromyalgia. J Psychosom Res 1997;42:607-13. [PubMed: 9226608]

Arnold LM, Hudson JI, Hess EV, Ware AE, Fritz DA, Auchenbach MB, Starck LO, Keck PE Jr. Family study of fibromyalgia. Arthritis Rheum 2004;50:944-52. [PubMed: 15022338]

Asmundson GJ, Coons MJ, Taylor S, Katz J. PTSD and the experience of pain: research and clinical implications of shared vulnerability and mutual maintenance models. Can J Psychiatry 2002;47:9307. [PubMed: 12553128] 
Begg MD, Parides MK. Separation of individual-level and cluster-level covariate effects in regression analysis of correlated data. Stat Med 2003;22:2591-602. [PubMed: 12898546]

Benedikt RA, Kolb LC. Preliminary findings on chronic pain and posttraumatic stress disorder. Am J Psychiatry 1986;143:908-10. [PubMed: 3717433]

Benjamin S, Morris S, McBeth J, Macfarlane GJ, Silman AJ. The association between chronic widespread pain and mental disorder: a population-based study. Arthritis Rheum 2000;43:561-7. [PubMed: 10728749]

Bergman S, Herrstrom P, Jacobsson LT, Petersson IF. Chronic widespread pain: a three year followup of pain distribution and risk factors. J Rheumatol 2002;29:818-25. [PubMed: 11950027]

Buchwald D, Goldberg J, Noonan C, Beals J, Manson S, Team A-S. Relationship between post-traumatic stress disorder and pain in two American Indian tribes. Pain Medicine 2005;6:72-9. [PubMed: 15669952]

Buskila D, Abramov G, Biton A, Neumann L. The prevalence of pain complaints in a general population in Israel and its implications for utilization of health services. J Rheumatol 2000;27:1521-5. [PubMed: 10852282]

Buskila D, Neumann L. Fibromyalgia syndrome (FM) and nonarticular tenderness in relatives of patients with FM. J Rheumatol 1997;24:941-4. [PubMed: 9150086]

Buskila D, Neumann L, Hazanov I, Carmi R. Familial aggregation in the fibromyalgia syndrome. Semin Arthritis Rheum 1996;26:605-11. [PubMed: 8989805]

Coghill RC, Sang CN, Maisog JM, Iadarola MJ. Pain intensity processing within the human brain: a bilateral, distributed mechanism. J Neurophysiol 1999;82:1934-43. [PubMed: 10515983]

Cohen H, Neumann L, Haiman Y, Matar MA, Press J, Buskila D. Prevalence of post-traumatic stress disorder in fibromyalgia patients: overlapping syndromes or post-traumatic fibromyalgia syndrome? Semin Arthritis Rheum 2002;32:38-50. [PubMed: 12219319]

Croft P. Testing for tenderness: what's the point?[comment]. J Rheumatol 2000;27:2531-3. [PubMed: 11093427]

Croft P, Burt J, Schollum J, Thomas E, Macfarlane G, Silman A. More pain, more tender points: is fibromyalgia just one end of a continuous spectrum? Ann Rheum Dis 1996;55:482-5. [PubMed: 8774169]

Croft P, Rigby AS, Boswell R, Schollum J, Silman A. The prevalence of chronic widespread pain in the general population. J Rheumatol 1993;20:710-3. [PubMed: 8496870]

Crook J, Weir R, Tunks E. An epidemiological follow-up survey of persistent pain sufferers in a group family practice and specialty pain clinic. Pain 1989;36:49-61. [PubMed: 2919095]

Davidson J, Smith R, Kudler H. Familial psychiatric illness in chronic posttraumatic stress disorder. Compr Psychiatry 1989;30:339-45. [PubMed: 2758806]

Dobie DJ, Kivlahan DR, Maynard C, Bush KR, Davis TM, Bradley KA. Posttraumatic stress disorder in female veterans: association with self-reported health problems and functional impairment. Arch Intern Med 2004;164:394-400. [PubMed: 14980990]

Eisen S, Neuman R, Goldberg J, Rice J, True W. Determining zygosity in the Vietnam Era Twin Registry: an approach using questionnaires. Clinical Genet 1989;35:423-32. [PubMed: 2736790]

Goldstein, H. Multilevel Statistical Models. Halstead Press; New York: 1995.

Gursoy S. Absence of association of the serotonin transporter gene polymorphism with the mentally healthy subset of fibromyalgia patients. Clin Rheumatol 2002;21:194-7. [PubMed: 12111622]

Horowitz M, Wilner N, Alvarez W. Impact of Event Scale: a measure of subjective stress. Psychosom Med 1979;41:209-18. [PubMed: 472086]

Hunt IM, Silman AJ, Benjamin S, McBeth J, Macfarlane GJ. The prevalence and associated features of chronic widespread pain in the community using the 'Manchester' definition of chronic widespread pain. Rheumatology 1999;38:275-9. [PubMed: 10325667]

Karlovic D, Buljan D, Martinac M, Marcinko D. Serum lipid concentrations in Croatian veterans with post-traumatic stress disorder,post-traumatic stress disorder comorbid with major depressive disorder, or major depressive disorder. J Korean Med Sci 2004;19:431-6. [PubMed: 15201512] 
Koenen KC, Harley R, Lyons MJ, Wolfe J, Simpson JC, Goldberg J, Eisen SA, Tsuang M. A twin registry study of familial and individual risk factors for trauma exposure and posttraumatic stress disorder. $\mathrm{J}$ Nerv Ment Dis 2002;190:209-18. [PubMed: 11960081]

Koenen KC, Lyons MJ, Goldberg J, Simpson J, Williams WM, Toomey R, Eisen SA, True WR, Cloitre M, Wolfe J, Tsuang MT. A high risk twin study of combat-related PTSD comorbidity. Twin Res 2003;6:218-26. [PubMed: 12855071]

Macfarlane GJ, McBeth J, Silman AJ. Widespread body pain and mortality: prospective population based study. BMJ 2001;323:662-5. [PubMed: 11566829]

Macfarlane GJ, Morris S, Hunt IM, Benjamin S, McBeth J, Papageorgiou AC, Silman AJ. Chronic widespread pain in the community: the influence of psychological symptoms and mental disorder on healthcare seeking behavior. J Rheumatol 1999;26:413-9. [PubMed: 9972978]

MacGregor AJ, Andrew T, Sambrook PN, Spector TD. Structural, psychological, and genetic influences on low back and neck pain: a study of adult female twins. Arthritis Rheum 2004;51:160-7. [PubMed: 15077255]

McBeth J, Macfarlane GJ, Hunt IM, Silman AJ. Risk factors for persistent chronic widespread pain: a community-based study. Rheumatology 2001;40:95-101. [PubMed: 11157148]

McLean SA, Clauw DJ, Abelson JL, Liberzon I. The development of persistent pain and psychological morbidity after motor vehicle collision: integrating the potential role of stress response systems into a biopsychosocial model. Psychosom Med 2005;67:783-790. [PubMed: 16204439]

Michalowicz BS, Pihlstrom BL, Hodges JS, Bouchard TJ Jr. No heritability of temporomandibular joint signs and symptoms. J Dent Res 2000;79:1573-8. [PubMed: 11023277]

Neumann L, Buskila D. Epidemiology of fibromyalgia. Curr Pain Headache Rep 2003;7:362-8. [PubMed: 12946289]

Papageorgiou AC, Silman AJ, Macfarlane GJ. Chronic widespread pain in the population: a seven year follow up study. Ann Rheum Dis 2002;61:1071-4. [PubMed: 12429537]

Pellegrino MJ, Waylonis GW, Sommer A. Familial occurrence of primary fibromyalgia. Arch Phys Med Rehabil 1989;70:61-3. [PubMed: 2916922]

Prescott E, Jacobsen S, et al. Fibromyalgia in the adult Danish population: II. A study of clinical features. Scand J Rheumatol 1993;22:238-242. [PubMed: 8235494]

Raphael KG, Janal MN, Nayak S. Comorbidity of fibromyalgia and posttraumatic stress disorder symptoms in a community sample of women. Pain Med 2004;5:33-41. [PubMed: 14996235]

Roy-Byrne P, Smith WR, Goldberg J, Afari N, Buchwald D. Post-traumatic stress disorder among patients with chronic pain and chronic fatigue. Psychol Med 2004;34:363-8. [PubMed: 14982142]

Sack WH, Clarke GN, Seeley J. Posttraumatic stress disorder across two generations of Cambodian refugees. J Am Acad Child Adolesc Psychiatry 1995;34:1160-6. [PubMed: 7559310]

SAS software, Version 8.1. SAS Institute Inc; Cary: 2000.

Sharp TJ. The prevalence of post-traumatic stress disorder in chronic pain patients. Curr Pain Headache Rep 2004;8:111-5. [PubMed: 14980145]

Sharp TJ, Harvey AG. Chronic pain and posttraumatic stress disorder: mutual maintenance? Clin Psychol Rev 2001;21:857-77. [PubMed: 11497210]

Sherman JJ, Turk DC, Okifuji A. Prevalence and impact of posttraumatic stress disorder-like symptoms on patients with fibromyalgia syndrome. Clin J Pain 2000;16:127-34. [PubMed: 10870725]

Shin L, McNally R, Kosslyn S, et al. A positron emission tomographic study of symptom provocation in PTSD. Ann N Y Acad Sci 1997;821:521-3. [PubMed: 9238243]

Smith B, Elliott A, Chambers W, et al. The impact of chronic pain in the community. Fam Pract 2001;18:292-299. [PubMed: 11356737]

Solter V, Thaller V, Karlovic D, Crnkovic D. Elevated serum lipids in veterans with combat-related chronic posttraumatic stress disorder. Croat Med J 2002;43:685-9. [PubMed: 12476477]

Taal L, Faber A. Burn injuries, pain and distress: exploring the role of stress symptomatology. Burns 1997;23:288-290. [PubMed: 9248635]

Torgersen S. The determination of twin zygosity by means of a mailed questionnaire. Acta Genet Med Gemellol (Roma) 1979;28:225-36. [PubMed: 297423] 
Walter B, Vaitl D, Frank R. Affective distress in fibromyalgia syndrome is associated with pain severity. Z Rheumatol 1998;2:101-4. [PubMed: 10025095]

Ware, JE.; Davies-Avery, A.; Brook, RH. The Rand Corporation (publication no. R-1987/1-HEW). Vol. 1. Santa Monica, CA: 1980. Conceptualization and measurement of health for adults in the Health Insurance Study: Model of health and methodology.

Weiss, D.; Marmar, C. The Impact of Event Scale -Revised. In: Wilson, J.; Keane, T., editors. Assessing psychological trauma and PTSD. Guildford; New York: 1997.

White KP, Harth M, Speechley M, Ostbye T. Testing an instrument to screen for fibromyalgia syndrome in general population studies: the London Fibromyalgia Epidemiology Study Screening Questionnaire. J Rheumatol 1999;26:880-4. [PubMed: 10229410]

White KP, Nielson WR, Harth M, Ostbye T, Speechley M. Chronic widespread musculoskeletal pain with or without fibromyalgia: psychological distress in a representative community adult sample. J Rheumatol 2002;29:588-94. [PubMed: 11908578]

Wohlfarth TD, van den Brink W, Winkel FW, ter Smitten M. Screening for Posttraumatic Stress Disorder: an evaluation of two self-report scales among crime victims. Psychol Assess 2003;15:101-9. [PubMed: 12674729]

Wolfe F. The relation between tender points and fibromyalgia symptom variables: evidence that fibromyalgia is not a discrete disorder in the clinic. Ann Rheum Dis 1997;56:268-71. [PubMed: 9166001]

Wolfe F, Skevington SM. Measuring the epidemiology of distress: the rheumatology distress index. J Rheumatol 2000;27:2000-9. [PubMed: 10955344]

Wolfe F, Smythe HA, Yunus MB, Bennett RM, Bombardier C, Goldenberg DL, Tugwell P, Campbell SM, Abeles M, Clark P, et al. The American College of Rheumatology 1990 Criteria for the Classification of Fibromyalgia. Report of the Multicenter Criteria Committee. Arthritis Rheum 1990;33:160-72. [PubMed: 2306288]

Yunus MB. The role of gender in fibromyalgia syndrome. Curr Rheumatol Rep 2001;3:128-34. [PubMed: 11286669]

Yunus MB. Gender differences in fibromyalgia and other related syndromes. J Gend Specif Med 2002;5:42-7. [PubMed: 11974674]

Yunus MB, Arslan S, Aldag JC. Relationship between body mass index and fibromyalgia features. Scand J Rheumatol 2002;31:27-31. [PubMed: 11922197]

Yunus MB, Khan MA, Rawlings KK, Green JR, Olson JM, Shah S. Genetic linkage analysis of multicase families with fibromyalgia syndrome. J Rheumatol 1999;26:408-12. [PubMed: 9972977] 
Table 1

Demographic and clinical characteristics of all twins and across terciles of the Impact of Events Scale

\begin{tabular}{|c|c|c|c|c|}
\hline \multirow{2}{*}{ Variable } & \multirow[b]{2}{*}{ Total $(n=3,740)$} & \multicolumn{3}{|c|}{ Impact of Events Scale Scores } \\
\hline & & Tercile $1^{a}(n=1,154)$ & Tercile $2(n=1,186)$ & Tercile $3(n=1,153)$ \\
\hline Monozygotic (\%) & 56 & 55 & 57 & 57 \\
\hline Age, mean (SD) & $33.0(14.8)$ & $34.3(15.7)$ & $32.5(15.0)$ & $32.1(13.7)$ \\
\hline Females $^{b}(\%)$ & 61 & 51 & 61 & 71 \\
\hline White (\%) & 87 & 87 & 88 & 86 \\
\hline Married $^{b}(\%)$ & 33 & 37 & 32 & 28 \\
\hline \multicolumn{5}{|l|}{ Education } \\
\hline Less than college $(\%)$ & 43 & 43 & 42 & 45 \\
\hline College $(\%)$ & 46 & 45 & 47 & 47 \\
\hline Graduate school $^{b}(\%)$ & 11 & 13 & 12 & 8 \\
\hline Body mass index, mean (SD) & $24.7(5.0)$ & $24.9(5.0)$ & $24.5(5.0)$ & $24.7(5.2)$ \\
\hline $\mathrm{CWP}^{b}(\%)$ & 7 & 4 & 8 & 10 \\
\hline $\operatorname{PTSD}^{b}(\%)$ & 3.8 & 1.3 & 2.3 & 8.4 \\
\hline Depression $^{b}(\%)$ & 20 & 9 & 18 & 34 \\
\hline
\end{tabular}

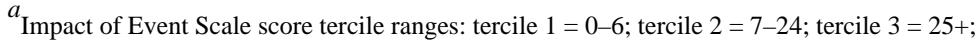

${ }^{b} P_{\text {trend }}<0.01$ 


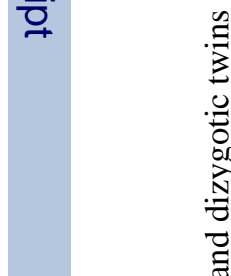

Z 


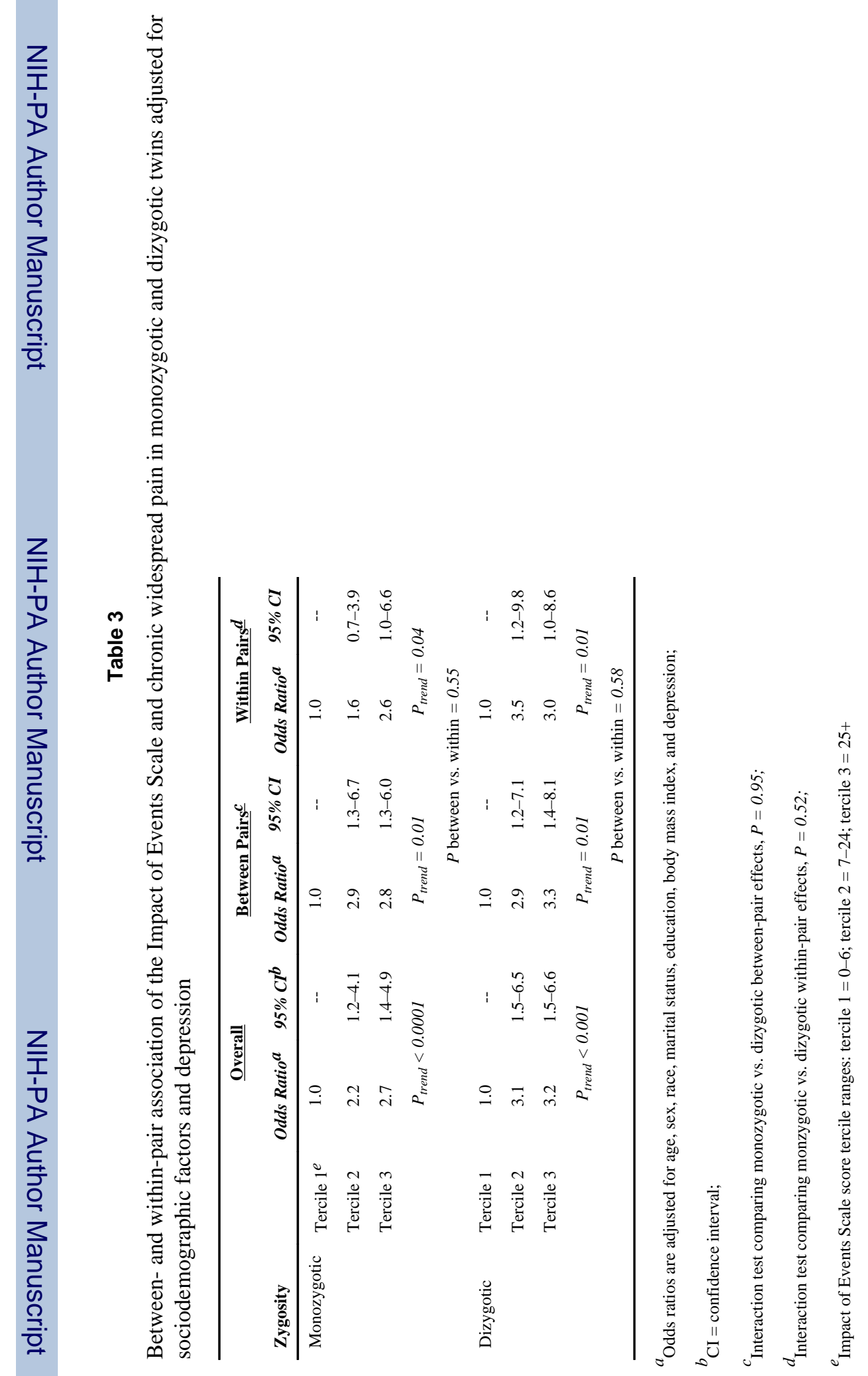

